\title{
Synthesis of Phenanthridine Derivatives via Oxidative Cyclization
}

\section{Key words}

phenanthridine derivatives

organoboron reagents

oxidative cyclization

manganese

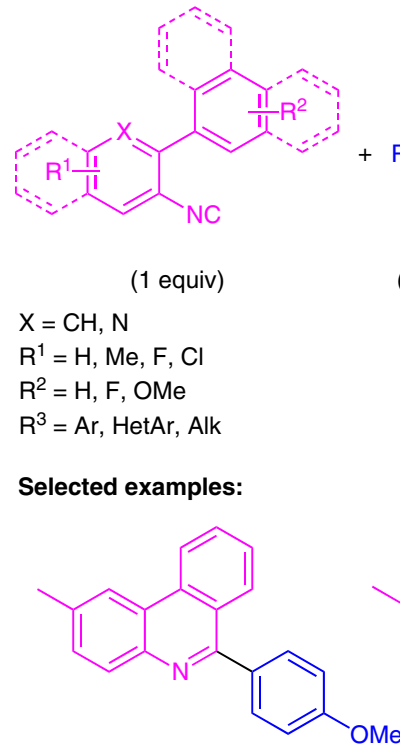

$84 \%$ yield<smiles>COc1ccc(-c2nc3ccc(C)cc3c3ccccc23)cn1</smiles>

$68 \%$ yield<smiles>c1ccc(-c2nc3cc4ccccc4nc3c3ccccc23)cc1</smiles>

$65 \%$ yield<smiles>CC(=O)c1ccc(-c2nc3ccc(C)cc3c3ccccc23)cc1</smiles>

$63 \%$ yield<smiles>Cc1ccc2nc(C3CCCCC3)c3ccccc3c2c1</smiles>

$76 \%$ yield<smiles>c1ccc(-c2nc3ccccc3c3c4ccccc4c4ccccc4c23)cc1</smiles>

$51 \%$ yield<smiles>Cc1ccccc1-c1nc2ccc(I)cc2c2ccccc12</smiles>

$76 \%$ yield<smiles>COc1ccc(-c2nc3ccc(F)cc3c3ccccc23)cc1</smiles>

$76 \%$ yield<smiles>COc1ccc2c(c1)c(-c1ccccc1)nc1ccc(C)cc12</smiles>

$68 \%$ yield
Significance: A straight-forward synthesis of a broad range of phenanthridine derivatives via a manganese-mediated annulation of 2-isocyanobiaryls with organoboronic acids has been disclosed. This rapid and divergent reaction furnishes the corresponding phenanthridine derivatives in good yield.
Comment: The reported reaction shows a simple pathway for the synthesis of phenanthridine frameworks out of readily accessible starting materials. Furthermore, mechanistic studies indicate that the reaction proceeds by the intramolecular homolytic aromatic substitution of an imidoyl radical intermediate.

SYNFACTS Contributors: Paul Knochel, Christoph Sämann

Dol: 10.1055/s-0032-1317737; Reg-No.: P15912SF 